\title{
COOPERACIÓN TRANSFronteriza y AMBIENTE EN AMÉRICA Central: el CASO de la Cuenca del Río SiXAola entre Costa Rica y Panamá
}

\author{
Transboundary Cooperation and Environment in Central America: the Case of Sixaola River Basin \\ between Costa Rica and Panama
}

Tania Rodríguez-Echavarría

Resumen: La cuenca transfronteriza del río Sixaola, localizada entre Costa Rica y Panamá, es considerada una región dinámica con múltiples facilidades para la cooperación. Su riqueza ambiental y cultural así como su precursor marco institucional y legal de cooperación binacional, entre otros factores, han hecho de esta frontera una región atractiva para importantes proyectos de cooperación ligados a la conservación del ambiente. Estos proyectos promovidos por actores exógenos, como organizaciones no gubernamentales internacionales, alianzas público-privadas y organizaciones financieras internacionales, tienen una importante influencia en la gestión ambiental de esta región fronteriza. El presente artículo estudiará su rol e influencia.

Palabras clave: fronteras, cooperación transfronteriza, ambiente, cuencas fluviales, actores internacionales.

Abstract: The Sixaola River basin, located between Costa Rica and Panama is considered a dynamic region, with an availability of multiple cooperation scenarios. Its environmental and cultural resources, as well as its early institutional and legal bi-national cooperation framework, among other factors, have made this border an attractive region for important cooperation initiatives on environmental conservation initiatives. These projects, carried out by foreign stakeholders such as non-governmental organizations (NGO's), publicprivate alliances and international financial organizations have an important influence on the environmental management of this border region. This article will examine its role and influence.

Keywords: borders, transboundary cooperation, environment, river basins, international actors.

\footnotetext{
Tania Rodríguez Echavarría, máster en Estudios de América Latina, Instituto de Altos Estudios de América Latina, IHEAL, Sorbonne Nouvelle, París. Doctorante en Geografía del Desarrollo de los Países Emergentes, Laboratorio SEDET, Universidad de Paris Diderot. Temas de especialización: cooperación y conflictos transfronterizos, gobernanza y medioambiente. Correo electrónico: tanucha@gmail.com.

Enviado a dictamen: 14 de enero de 2013. Aprobación: 26 de abril de 2013.

Revisiones: 1.
} 


\section{Introducción: el estudio de las fronteras centroamericanas}

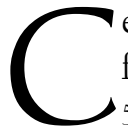

entroamérica es un istmo marcado por su fragmentación política, ya que en sus escasos 523160 kilómetros cuadrados se pueden encontrar siete Estados. Esta estrecha franja de tierra representa un puente cultural y ambiental entre dos continentes; Centroamérica es así un espacio de transición natural y de paso, alrededor del cual se mueven no sólo bienes, sino también personas.

La pertinencia del estudio de las fronteras fue cuestionada en las últimas décadas debido a la intensificación de los procesos de globalización y a las iniciativas de integración virtual, política o económica, así como a la creciente firma de tratados de libre comercio, que presentaban un mundo dominado por un mercado mundial "sin patria" donde las fronteras, símbolo de la modernidad, ya no tenían cabida (Machado de Oliveira, 2009: 19). Sin embargo, la desaparición de las fronteras es un mito, ya que su función y su impacto siguen determinando no sólo las relaciones internacionales - conflictos por definición de límites, restricciones a la migración, entre otros ejemplos-, sino además las dinámicas cotidianas que se dan en las regiones fronterizas - por ejemplo, contrabando o paso de aduanas-.

El estudio de las fronteras centroamericanas no sólo es pertinente, sino que es necesario; primero porque un porcentaje importante de la región centroamericana está marcado por su cercanía a una frontera, y segundo debido a la complejidad y diversidad de las dinámicas que se desarrollan alrededor de ellas. Las fronteras forman parte de un sistema complejo alrededor del cual se desarrollan múltiples actividades, las cuales son impulsadas por actores locales, nacionales e internacionales. Estas actividades pueden ser formales, como los tratados de cooperación firmados entre gobiernos o los proyectos de cooperación desarrollados por actores internacionales. Asimismo, las dinámicas fronterizas pueden ser informales, es decir, actividades que se dan desde la cotidianidad de los habitantes de las fronteras y que no están formalizadas por convenios o tratados. Algunos ejemplos pueden ser las redes de turismo, los intercambios culturales y comerciales, o actividades ilícitas como el contrabando y el narcotráfico, las cuales se dan con mayor facilidad en estas regiones fronterizas ${ }^{1}$ debido a la falta de vigilancia y a la existencia de "puntos ciegos". 2

Las fronteras centroamericanas son así regiones dinámicas que han adquirido importancia estratégica debido a su posición geopolítica ${ }^{3}$ y a su riqueza ambiental -biodiversidad y recursos naturales claves, como las cuencas hidrográficas-. La importancia ambiental de estas regiones fronterizas fue utilizada como un argumento articulador durante el proceso de transición a la democracia, periodo en el que se presentaron como "santuarios ecológicos" y culturales, cuyo desarrollo y conservación podía motivar una integración de la región desde "abajo", desde las fronteras. Este nuevo escenario motivó que una gran diversidad de actores endógenos —nacionales y locales - y exógenos -internacionales y transnacionales - promovieran paulatinamente la firma de acuerdos, proyectos y programas que buscaban principalmente el desarrollo y la conservación de estas regiones. ${ }^{4}$

Sibien la presencia y la influencia de actores exógenos en la región no es reciente, ${ }^{5}$ se puede constatar a partir de la década de los años noventa la incursión de proyectos y programas de cooperación ambiental que fueron impulsados por actores exógenos —organizaciones no gubernamentales (ONG) internacionales, agencias de cooperación, bancas de desarrollo, entre otros-.

En Centroamérica, la frontera entre Costa Rica y Panamá, así como la frontera compartida por Guatemala, Honduras y El Salvador, conocida como el Trifinio, fueron consideradas por la cooperación internacional como enclaves conducentes a la cooperación, en los cuales se podían ejecutar con mayor facilidad acciones de cooperación ambiental debido a la falta de conflictos entre los Estados y a su proximidad cultural. Estos puntos geográficos se convirtieron en verdaderos laboratorios y en ellos se han venido implementando estrategias de conservación y de gestión integrada de cuencas. No es por lo tanto extraño que estas dos fronteras sean consideradas hoy en día como sitios 
pioneros en los que se han desarrollado los marcos legales de cooperación más completos y avanzados de la región (Medina, 2009: 42).

El presente artículo se centrará en analizar las dinámicas de cooperación en materia ambiental que se dan en la parte Caribe de la frontera entre Costa Rica y Panamá, particularmente en el tramo fronterizo donde se encuentra la cuenca del río Sixaola. Nuestro objetivo central será el de contribuir al debate actual sobre la cooperación transfronteriza a través del análisis del juego de actores que se da alrededor de la gestión ambiental de esta frontera desde un enfoque multidisciplinario.

Para esto, se tratarán de confrontar tres hipótesis: la primera sostiene que existe una relación ineludible entre las fronteras centroamericanas y el ambiente. La segunda plantea que en la cuenca del río Sixaola existen múltiples proyectos de cooperación en materia ambiental impulsados mayoritariamente por actores exógenos como ONG internacionales y organismos intergubernamentales (OIG), los cuales cuentan con recursos económicos y equipos técnicos que los Estados no tienen. Y la tercera propone que estos proyectos y actores tienen una creciente influencia e incidencia en la gestión ambiental de esta cuenca, influencia que les ha permitido introducir en la gestión local sus preocupaciones e intereses - adaptación al cambio climático o gestión integrada de cuencas, entre otros factores-, así como la creación de espacios de gobernanza que buscan gestionar los ecosistemas compartidos, como comisiones y comités de cuenca.

A continuación se presentará esta región de frontera, para después exponer brevemente los debates sobre la relación entre las fronteras y el ambiente. Posteriormente, se procederá a analizar el contenido y el modo de ejecución de los proyectos identificados en esta cuenca con el fin de elucidar cómo éstos funcionan y qué papel juegan los actores exógenos que los alientan.

\section{Metodología}

Los resultados presentados en este artículo forman parte de un proceso de investigación doctoral activo que tiene como objetivo analizar de forma comparativa las dinámicas de cooperación y de conflicto que se han venido desarrollando en los últimos 20 años alrededor de la gestión de la cuenca del río San Juan —entre Costa Rica y Nicaragua - y la cuenca del río Sixaola —entre Costa Rica y Panamá-.

La información empírica que presentaremos fue obtenida durante los años 2011-2012 a través de la realización de alrededor de 75 entrevistas a profundidad semiestructuradas a actores gubernamentales - nacionales y locales-, actores de la sociedad civil - autoridades indígenas y asociaciones de desarrollo-, funcionarios públicos - como ministerios o cancillerías-, secretarios de las comisiones de cooperación binacionales, investigadores, líderes comunitarios, técnicos de ONG y cooperativas. Estas entrevistas fueron ideadas para identificar la red de actores fronteriza y definir con mayor especificidad el tipo de relaciones que entre ellos existía -influencia, cercanía, confianza, cooperación, tensión y conflicto-, así como para determinar el modo de funcionamiento de dichos proyectos.

\section{Breve descripción socio-espacial de la cuenca del río Sixaola}

La cuenca del río Sixaola es una región transfronteriza compartida entre Costa Rica y Panamá donde se puede observar una importante continuidad ambiental, así como una homogeneidad cultural propia de la vertiente Caribe de la región centroamericana. La proximidad cultural es el resultado de una historia en común de enclave bananero y de asilamiento que forjó, a pesar de conflictos puntuales, un ambiente propicio para la cooperación.

El río Sixaola delimita la parte de la frontera entre Panamá y Costa Rica que está situada en la vertiente Caribe. Este río nace en las montañas de Talamanca, en Costa Rica, y en la Cordillera Central de Panamá, para desembocar en el océano Atlántico cubriendo un área de 2839,6 kilómetros cuadrados (Franklin, 2007: 8). Cabe aclarar el concepto de cuenca hidrográfica. Una cuenca hace referencia a un espacio geográfico que articula 
tanto los recursos hídricos superficiales y subterráneos y los ecosistemas existentes, como los poblados y sus actividades productivas. Las cuencas se definen así como "una región geográfica natural drenada por uno o varios ríos, que está delimitada por una divisoria de aguas y cuyo curso principal desemboca en un depósito natural o artificial, directamente al mar, o a una terminal cerrada, ya sea lago o mares internos." (Hernández, López y Jiménez, 2009: 15). Una cuenca es considerada como transfronteriza cuando en su delimitación se encuentran comprendidos los límites administrativos y políticos de dos o más Estados (Maganda, 2008: 175) (ver mapa l).

Se presenta así una interesante dicotomía: por un lado, la cuenca implica una continuidad ambiental que se ve fragmentada por un límite político artificial. Esta división tiene impactos considerables en cuanto a su gestión, ya que muchas veces los Estados gestionan de forma divergente estos ecosistemas que están interrelacionados ya que cuentan con sus propias legislaciones y prioridades políticas (ver tabla l).

Costa Rica y Panamá son, a diferencia de otros países centroamericanos, dos Estados que cuentan con una democracia relativamente consolidada ya que poseen instituciones estables, pero, aun con estas condiciones, sus regiones fronterizas han permanecido excluidas y han estado marcadas por profundas desigualdades que las han hecho aún más vulnerables.

Esta región fronteriza ha estado históricamente en una posición periférica y marginal debido a su lejanía de los centros de poder - generalmente localizados en las capitales - y a su aislamiento geográfico. Su rezago social y económico con respecto al resto de Costa Rica y Panamá es el resultado de décadas de olvido por parte de los gobiernos centrales, los cuales han tenido una débil presencia gubernamental - ausencia de oficinas, de planes de desarrollo y de inversión-. Este vacío dejado por el aparato estatal generó un terreno fértil que motivó y facilitó la instalación de actores exógenos — tanto económicos como de la cooperación internacional-, los cuales han tenido una importante incidencia en el poblamiento - empresas transnacionales bananeras-, el ordenamiento territorial y el desarrollo productivo de estas regiones.

Según el Banco Interamericano de Desarrollo (BID), las poblaciones que han residido en esta cuenca han estado aisladas cultural y económicamente, y se estima que un 95\% de la población de la cuenca alta es indígena, más específicamente de los grupos bri bri, cabécar y ngöbe buglé, los cuales viven en condiciones de pobreza. En la cuenca baja de los dos lados de la frontera se pueden encontrar poblaciones mestizas, chinas y afrocaribeñas - esstas últimas se extienden por toda la costa Caribe de Centroamérica (Rodríguez, 2009) - así como grupos de extranjeros que se han convertido en propietarios de muchos de los terrenos costeros debido al desarrollo turístico de la zona.

\section{Fronteras, ambiente y cooperación}

\section{Fronteras: espacios de separación y de proximidad}

Para analizar la complejidad de las dinámicas de cooperación transfronteriza que buscan gestionar ecosistemas compartidos - como las cuencas hidrográficas-, es necesario clarificar el término frontera y lo que implica trabajar en zonas fronterizas.

El concepto frontera ha evolucionado a través del tiempo. Inicialmente este término tenía una fuerte connotación militar y hacía referencia a "hacer frente" o "ir al frente" (Foucher, 1991). Esta definición fue paulatinamente evolucionando y, con la construcción de los Estados nacionales, la frontera adquirió un rol protagónico al asumir la función de "perímetro" del conjunto espacial que es el Estado (Foucher, 1997: 20). La invención de la frontera permitió delimitar un espacio dentro del cual se aspiraba a generar cohesión interna y homogeneidad económica (Foucher, 1997: 20). Las fronteras adquirieron así la función de división del espacio para la organización política en territorios. El territorio no es un concepto neutro y no es sinónimo de espacio, ya que espacio es una noción más abstracta, general e impersonal, mientras que desde una perspectiva geográfica el territorio es una "porción de la superficie terrestre apropiada por un grupo social 
para asegurar su reproducción y la satisfacción de sus necesidades vitales" (LeBerre, 1992).

Una definición pensada desde las ciencias sociales que puede resumir muchas de las dimensiones del concepto "frontera" es la propuesta por Hélène VelascoGraciet y Christian Bouquet. Para ellas, la frontera nacional es:

[...] un territorio socialmente determinado, expresión espacial de la soberanía, de poder y de ciudadanía, compuesto por actores, los cuales han interiorizado desde su infancia, las normas de una ideología nacional que designó ese territorio como portador de esta identidad nacional (Velasco-Graciet y Bouquet, 2006: 9).

Esta división del mundo impone un orden y establece un sentimiento de pertenencia a una sociedad imaginada. Las fronteras marcan así los límites de la ciudadanía y el rango de acción del Estado. En las fronteras se puede percibir una ruptura con respecto a la continuidad cultural de los territorios nacionales; alrededor de ella se articula una identidad propia que se ha venido construyendo a través de la proximidad que se tiene al otro, al vecino que vive del otro lado de la frontera (Rodriguez, 2009).

\section{La línea de la frontera o región transfronteriza}

Según Foucher, en su libro Frentes y fronteras, la frontera como línea o perímetro nos remite a una noción más política y jurídica, mientras que el concepto "zona" es un concepto más geográfico (Foucher, 1991: 48) ya que la noción de zona hace referencia a una unidad espacial más grande que integra múltiples elementos y presenta la frontera como un espacio en sí mismo, un "entre dos".

Para efectos de esta investigación, analizaremos la frontera no como una línea, sino más bien como un objeto espacial más vasto, es decir, como una región compleja alrededor de la cual se desarrollan múltiples juegos de actores a diferentes escalas espaciales.

La frontera es así una "región dinámica" marcada por la colindancia y la continuidad cultural y ambiental
(Morales, 2010: 187). Esta región, según su grado de porosidad, puede ser o no ser transfronteriza; según Reitel y Zander, por transfronterizo se puede entender un espacio que "es atravesado, de paso y de transgresión" (Reitel y Zander, 2004: 1), es decir, una región donde hay movimiento y dinamismo, que se extiende más allá de los límites de los Estados y en la que sus habitantes, a pesar de ser ciudadanos de diferentes Estados, comparten características culturales, antecedentes históricos y significativos intercambios comerciales. La región transfronteriza es un espacio que "traspasa de esta forma las líneas de separación y origina una integración entre los límites colindantes" (Morales, 2010: 186). Fourny y Amilhat-Szary aseguran que estas dinámicas son "lo que pasa en la frontera cuando la línea de separación no pretende bloquear las prácticas y el sentimiento de pertenencia" (Amilhat-Szary y Fourny, 2006: 9). Es importante destacar que generalmente las regiones transfronterizas carecen de estatuto jurídico y no son siempre reconocidas por los Estados (Morales, 2010: 187).

Estas regiones generalmente están más conectadas con el país vecino que con el centro de los países a los que pertenecen; la yuxtaposición de dos territorios, como es el caso de la frontera entre Costa Rica y Panamá, facilita que se den condiciones propicias para el desarrollo de actividades productivas y de cooperación. Asimismo, la existencia de un tipo de cambio y de diferentes legislaciones confiere a estas regiones una ventaja comparativa con respecto a otras, condiciones que motivan la instalación de actividades productivas a escala transfronteriza, así como el contrabando de bienes que son generalmente más baratos en un lado que en otro de la frontera (Machado de Oliveira, 2009: 22). Esta situación particular propia de estas regiones es aprovechada tanto por los pobladores, como por los empleadores, las empresas y los mismos organismos de cooperación.

\section{Fronteras y ambiente}

Antiguamente, las fronteras eran consideradas como naturales cuando su trazado correspondía a un 
elemento natural que hacía visible y material una ruptura espacial - montañas y ríos-. Posteriormente, desde la comunidad científica - especialmente desde la geografía - se emprendió un proceso de reflexión que cuestionó esta relación entre frontera y naturaleza, llegando a la conclusión de que las fronteras son en realidad construcciones sociales y que el argumento natural había sido utilizado para legitimar su trazado para así presentarlo como un hecho indiscutible, una realidad preexistente o algo que siempre había estado ahí.

A partir de la década de los años sesenta, esta vez de la mano de las organizaciones internacionales, se da un resurgimiento de la relación entre ambiente y fronteras. Debido al creciente interés mundial por las problemáticas ambientales, se fraguaron una serie de iniciativas que buscaban la protección del ambiente a través principalmente de la creación de áreas protegidas - parques naturales y áreas de conservación-, así como numerosas teorías y metodologías de gestión que buscaban organizar la naturaleza en espacios protegidos. Estas iniciativas impulsadas por organizaciones internacionales - Unión Internacional para la Conservación de la Naturaleza (UICN), ${ }^{6}$ World Wildlife Fund (WWF), The Nature Conservancy (TNC) - conferían, como bien lo afirma Debarbieux, valores simbólicos e institucionales a objetos espaciales naturales - montañas, bosques, humedales y otros(Debarbieux, 2006: 79).

La "naturalización" de las fronteras es un fenómeno que se da en este nuevo escenario mundial. Las regiones fronterizas, por ser zonas marginales y aisladas, se mantuvieron poco urbanizadas y poco pobladas, lo que permitió que se conservara una importante biodiversidad. Esta riqueza natural desordenada en periferias olvidadas por los gobiernos centrales fue percibida como una problemática compartida, un bien universal que debía ser preservado por todos - ya que la naturaleza no conoce de límites ni de fronteras. Este discurso transforma el estatus del límite y redefine la percepción que se tenía de las fronteras políticas, obligando por lo tanto a la reestructuración de las cooperaciones (Fourny, 2005: 97).
Un ejemplo de esta naturalización de las fronteras son las Áreas Naturales Protegidas Transfronterizas (ANPT) de la UICN. Esta organización ha venido tratando el tema transfronterizo desde la década de los ochenta y definió las ANPT como:

Cualquier área terrestre o marina traslapada con una o más líneas limítrofes entre Estados, unidades sub-nacionales como provincias y regiones, áreas autónomas o áreas situadas fuera de los límites de la soberanía o jurisdicción nacionales, cuyas partes integrales estén especialmente dedicadas a la protección y el mantenimiento de la biodiversidad biológica, así como los recursos naturales y culturales asociados con la misma, y que sea manejada cooperativamente con fundamentos legales o por cualquier otro medio efectivo (Rodriguez, 2009: 8).

Las ANPT representan actualmente casi 200 complejos, integrados por más de 800 áreas naturales protegidas, que fungen para la UICN como un mecanismo para reducir tensiones y promover la cooperación entre países a través de la cooperación multinivel y "la buena voluntad" (Rodríguez, 2009: 8).

De esta forma, espacios antes no ocupados, noman's lands, que no generaban interés, son recalificados material y simbólicamente por la presencia de la naturaleza (Fourny, 2005: 111). La naturaleza deja de ser percibida como un objeto que divide y pasa a ser percibida como un objeto que crea lazos. Se presencia así una resemantización de la frontera, ya que se introduce la noción de "región natural", la cual sostiene que la naturaleza es el fundamento legitimador de una cultura regional de extensión transfronteriza, que valoriza unidades geográficas grandes y englobantes que siguen la ley natural y no las divisiones humanas. Las regiones naturales son presentadas en el discurso de la cooperación internacional como espacios públicos e inmateriales, los cuales son responsabilidad de los Estados y de la comunidad internacional. Se propone así sobrepasar las divergencias políticas y ejecutar acciones que armonicen las prácticas y las formas de gestión. El espacio natural fronterizo 
traspasa lo local y lo nacional ya que es un patrimonio global (Fourny, 2005: 108 y 109).

El reconocimiento de esta naturaleza compartida es uno de los criterios - junto con la continuidad cultural- que intervienen en la identificación de espacios transfronterizos. La naturaleza como un elemento transfronterizo justifica el desarrollo de actividades de cooperación entre estructuras ambientalistas - nacionales e internacionales-e instituciones.

\section{Iniciativas de cooperación para la conservación} de las cuencas transfronterizas: entre cooperación formal y cooperación internacional

\section{Cooperación formal desde el Sistema de Integración} Centroamericano: conservar el ambiente para construir la paz

Por cooperación formal se entenderá la cooperación que se lleva a cabo de forma vertical, es decir, desde arriba hacia abajo, ya que es motivada y pensada desde los gobiernos o desde los sistemas de integración como el Sistema de Integración Centroamericano (SICA) (Machado de Oliveira, 2009). Es reconocida por los Estados y conduce generalmente a acuerdos o leyes.

Elinterés ambiental porlasfronterascentroamericanas data de la década de los años noventa con la implementación de iniciativas como el Sistema de Áreas Protegidas para la Paz y la creación de la Comisión Centroamericana de Ambiente y Desarrollo dentro del SICA. Promover el desarrollo sostenible en la región se torna una estrategia para promover la integración a partir de un interés común: la protección de un bien universal. El desarrollo sostenible ${ }^{7}$ abre también la puerta a otros temas ambientales que son introducidos progresivamente, como la gestión integrada del agua, la gestión del riesgo y, más recientemente, la adaptación al cambio climático. En 1995, con la firma del Acuerdo para el Desarrollo Sostenible Fronterizo en América Central, los gobiernos de la región expresan su interés por luchar contra la marginalidad de estas regiones fronterizas y proponen alrededor de 15 proyectos para asegurar, gestionar y desarrollar estas regiones transfronterizas, las cuales son vistas como espacios para "construir en conjunto" (Bovin, 1997). Es así como el desarrollo de estas regiones transfronterizas es visto como un requisito necesario para la integración (Fourny, 2005). Aparece también a finales de la década de los noventa el Plan de Acción para la Gestión de los Recursos Hídricos (1999), el cual buscaba promover el desarrollo de los recursos hídricos garantizando un uso racional -eficiencia y equidad - y sostenido - con base en una función social-. Este plan buscaba modernizar los marcos legales e institucionales y fortalecer las capacidades institucionales desde lo nacional. Además, pretendía motivar la cooperación regional y definir políticas de cooperación entre países fronterizos para así mejorar la gestión de los recursos hídricos. Las cuencas, y en específico las cuencas transfronterizas, aparecen como unidades clave para la gestión integrada y se motiva abiertamente a los Estados a participar y a colaborar desde una perspectiva transfronteriza. Es importante destacar que la UICN participó activamente en la construcción de este plan, así como la Organización de Estados Americanos (OEA); este último organismo aportó importantes insumos científicos para la discusión gracias a un estudio del Programma UNESCO/ OEA ISARM sobre los Acuíferos Transfronterizos de las Américas. ${ }^{8}$ Es importante destacar que, hasta la fecha, esta estrategia no se ha logrado aplicar como se había previsto en los diferentes países de la región.

\section{Cooperación formal entre Estados}

Costa Rica y Panamá, como ya se mencionó, cuentan con el marco de "cooperación transfronteriza más desarrollado de la región centroamericana" (Girot y Granados, 1997). Representantes de ONG de carácter internacional como UICN, TNC y la Unidad Regional de Asistencia Técnica (RUTA) ${ }^{9}$ afirmaron durante las entrevistas que, junto con su importancia ambiental, el hecho de que esta frontera fuera considerada como una de las más pacíficas del istmo y conducentes a la cooperación, fue un factor determinante para escogerla como espacio para implementar sus proyectos. Muchos 
de estos actores se mostraron de acuerdo en que esta característica hace aún más viable la consecución de los objetivos planteados en estos proyectos.

Efectivamente, esta frontera es sin duda la que cuenta con el marco de cooperación binacional más desarrollado, el cual tiene sustento en el Convenio para el Desarrollo Fronterizo Costa Rica-Panamá, firmado en 1992 pero que entra en vigencia en 1995. Este convenio establece una Comisión Binacional Permanente como órgano de decisión y una Secretaría Ejecutiva con representantes en cada uno de los países; la Comisión es la responsable de dar seguimiento a las actividades y a los acuerdos generados. Existen además subcomisiones mixtas que tratan temas específicos como ambiente, gobiernos locales, seguridad, migración y turismo, entre otros. En esta Comisión participan tanto actores de la sociedad civil, como representantes de los ministerios, de los gobiernos locales, la policía y las cancillerías, entre otros (Matul, 2007).

Paralelamente a este convenio entre ambos países existe además un acercamiento comercial que data de 1973, cuando se firmó el Tratado de Libre Comercio e Intercambio Preferencial. Las relaciones comerciales fueron consolidadas en 2007 con el Tratado de Libre Comercio entre Costa Rica y Panamá (Matul, 2007: 107). Además, en 2013 los presidentes firmaron un acuerdo para que los habitantes de los poblados fronterizos de Panamá pudieran cruzar la frontera y acceder al territorio costarricense, unidos sólo por una cédula transfronteriza; se espera que en los próximos meses esta medida se extienda a los habitantes fronterizos del lado costarricense.

De esta forma, estos dos países cuentan con relaciones diplomáticas e intergubernamentales dinámicas y fluidas. Cabe acotar que aún se mantienen restricciones en materia migratoria y aduanera, así como problemas prácticos debido a las asimetrías legales einstitucionales que existen, particularmente en materia laboral y ambiental. Estas asimetrías dificultan la coordinación entre los gobiernos y la puesta en práctica de medidas de forma binacional. Por ejemplo, la legislación ambiental — categorías de manejo, la interdicción de construir en la milla marítima, ${ }^{10}$ entre otros- es más restrictiva en Costa Rica que en Panamá, lo que dificulta que se puedan proteger de la misma manera los ecosistemas compartidos.

\section{La cooperación internacional en la cuenca del Sixaola}

Paralelamente a la cooperación emprendida por los Estados y por el SICA, alrededor de la cuenca del río Sixaola se pueden identificar múltiples proyectos de cooperación impulsados por actores no gubernamentales, organizaciones intergubernamentales y agencias de cooperación. Es interesante acotar que muchos de estos proyectos de cooperación tienen acuerdos con los gobiernos nacionales y locales, al igual que con organizaciones locales, las cuales son muchas veces subcontratadas para la ejecución de los proyectos.

Organizaciones como la UICN, TNC, WWF, así como organismos intergubernamentales como el BID, han identificado esta cuenca como una región transfronteriza estratégica debido a su importante biodiversidad (Franklin, 2007). El BID considera que esta zona "representa una prioridad en conservación" debido a que en ella se encuentra una importante biodiversidad, así como importantes ecosistemas marinos, ya que sólo en la cuenca del río Sixaola se pueden encontrar seis áreas protegidas que cubren 143000 hectáreas y representan el 40,3\% de los espacios protegidos de Panamá y el 27,9\% de Costa Rica (Matul, 2007: 107). Sólo en la parte alta de esta cuenca que corresponde al Parque Internacional La Amistad Caribe, ${ }^{11}$ se encuentran alrededor de un 4\% de las especies terrestres mundiales (Franklin, 2007: 9).

El número creciente de iniciativas de cooperación que buscan desarrollar proyectos para la conservación de estos ecosistemas compartidos evidencia un interés internacional por la región. Durante este proceso de investigación se lograron identificar una serie de proyectos y de programas cuyo financiamiento y ejecución depende de actores exógenos, es decir, actores de la cooperación internacional, ya sean ONG internacionales, bancos de desarrollo o agencias de cooperación. La tabla 2 presenta un breve resumen de 
los principales proyectos ejecutados en los últimos años en esta región transfronteriza.

\section{De lo global a lo local: el oligopolio de la conservación}

Entre los resultados generados por el proceso de investigación -entrevistas y análisis de contenido de los documentos de proyecto- se pudo observar que esta frontera es percibida - sobre todo por los representantes de las ONG internacionales- como una zona de oportunidad que aporta significativas ventajas al momento de ejecutar un proyecto de cooperación. Ante todo manifestaron que trabajar en zonas fronterizas permite a un solo proyecto tener impactos en dos países a la vez, condición que es vista como positiva por los principales donantes que evalúan los proyectos -Cooperación Noruega, Cooperación Danesa, Ministerio de Ambiente Alemán, USAID-.

Tantolos representantes de las ONGinternacionales como los funcionarios públicos de los ministerios y autoridades ambientales - Ministerio de Ambiente y Energía de Costa Rica y la Autoridad Nacional del Ambiente en Panamá- están de acuerdo con que las ONG internacionales tienen mayor capacidad de acción que los Estados en regiones transfronterizas, ya que no están sometidas a los procedimientos diplomáticos - cancillerías y asambleas nacionalesni a la burocracia estatal al momento de ejecutar un proyecto en zona fronteriza. Tienen además la potestad de invertir fondos en múltiples países, mientras que algunos Estados, por una cuestión de soberanía, no pueden ejecutar su presupuesto nacional fuera de su territorio - éste es el caso de Costa Rica-. Las ONG internacionales y organismos como el BID pueden así actuar con mayor facilidad y menos restricciones, ya que pueden acceder con mayor facilidad a fondos internacionales, pueden ejecutar con mayor efectividad sus presupuestos, y cuentan además con equipos de investigadores y técnicos capacitados para ejecutar proyectos y asumir los vacíos institucionales.
Se puede además observar que, si bien estos proyectos son ejecutados localmente, muchos forman parte de iniciativas globales, las cuales son concebidas desde foros internacionales o por expertos desde las oficinas centrales de dichas organizaciones. Éste es el caso de los proyectos de la UICN, los cuales están adscritos a iniciativas mundiales como Agua y Naturaleza, conocida también como WANI por sus siglas en inglés - Water and Nature IniciativeWANI nace durante el II Foro Mundial del Agua en el año 2000 y de él se desprende el documento Visión Mundial del Agua (2005), en el cual se define como objetivo central mejorar la situación de las cuencas con el fin de que éstas tengan una mayor resiliencia al cambio climático conservando los ecosistemas y los medios de vida. Esta iniciativa se ejecuta en 12 cuencas en 30 países de todo el mundo. Otra iniciativa de la UICN que enmarca estos proyectos es BRIDGE, o "puente" en español, - Building River Dialogue and Governance. Construyendo Diálogo y Gobernanza en los Ríos-, la cual busca generar capacidades para la gobernanza en cuencas transfronterizas. Es importante destacar que la UICN cuenta con diez oficinas regionales y 24 oficinas nacionales, lo que facilita la importación de estas iniciativas a diferentes regiones del mundo de forma simultánea. Por su parte, TNC, si bien es una organización esencialmente estadounidense que se ha replegado en los últimos años hacia América Latina, estuvo presente en 28 países y su Programa de Parques en Peligro fue implementado en 12 parques en todo el continente americano. Estas iniciativas no sólo aportan elementos teóricos y metodologías que guían los proyectos, sino que establecen metas que deben ser alcanzadas en periodos de tiempo específicos. Los proyectos están así inmersos en un sistema mundial altamente jerarquizado que Dumoulin y Rodary califican como "oligopolio de la conservación", es decir, un sistema gobernado por unos pocos (Dumoulin y Rodary, 2005: 70). Las regiones donde son ejecutados estos proyectos se convierten así en verdaderos laboratorios de conservación donde se ejecutan y validan las estrategias e iniciativas que son pensadas por este oligopolio mundial. 
Según los proyectos estudiados, se pudo identificar que existen tres modalidades de ejecución de proyectos y programas según los actores que intervienen:

\section{Proyectos de cooperación promovidos por ONG internacionales} - UICN, TNC, y otras - y los financiados por agencias internacionales de cooperación para el desarrolloy directamente por gobiernos. Estos proyectos, como mencionamos anteriormente, son conceptualizados por los equipos técnicos de estas organizaciones en foros, en oficinas o en comisiones científicas, para después ser sometidos a las agencias internacionales de cooperación, ya sea durante una convocatoria para presentar proyectos o durante un proceso de negociación entre la ONG y la agencia de cooperación. Éste fue el caso del Proyecto Alianzas, de la UICN y la agencia de cooperación Noruega, o del Proyecto Gobernanza y Cambio Climático en las cuencas transfronterizas de la UICN, este último financiado por el gobierno alemán. Los proyectos responden así a una serie de temas y prioridades predefinidos por este oligopolio a través de declaraciones internacionales como los Objetivos de Desarrollo del Milenio y las convenciones sobre cambio climático.

Es común que, una vez aprobados los proyectos, éstos sean presentados al público meta, es decir, a los actores locales, a través de talleres de información y consulta, pero las organizaciones locales asociaciones indígenas o asociaciones de desarrollo, entre otras - son raramente invitadas a participar en su concepción.

Cada vez más se recurre a alianzas entre ONG internacionales, o entre una ONG internacional y una ONG local, para presentar los proyectos a las agencias de cooperación. Las ONG locales tienen un rol cada vez más importante ya que las ONG internacionales se apoyan en ellas para ejecutar sus proyectos debido a que cuentan con una importante legitimidad y proximidad con las comunidades. Sin embargo, la ONG internacional mantiene siempre una posición jerárquica ya que coordina, gestiona los fondos y evalúa los resultados. Éste es el caso de la ONG local Corredor Biológico Talamanca Caribe, la cual, como se puede observar en los gráficos 1 y 2 , tiene por un lado fuertes lazos con las ONG internacionales y a la vez es percibida como una organización que genera confianza.

\section{Proyectos de cooperación promovidos por organizaciones} intergubernamentales como el BID a través de préstamos y donaciones. El BID, como el Banco Mundial, a partir de la década de los ochenta vivió un "reverdecimiento" que implicó su reorientación y la creación del Fondo para el Medio Ambiente Mundial (FMAM), organismo de donde procede la donación que financia el Proyecto para la Gestión Integrada de Ecosistemas de la Cuenca Binacional del Río Sixaola (BID GEF).

Los proyectos financiados por el BID son sumamente complejos desde su concepción hasta su ejecución, ya que son préstamos o donaciones que se otorgan a los Estados, por lo que implican todo un proceso interno de debate que pasa muchas veces por las asambleas legislativas. En el caso de la cuenca del río Sixaola hay dos proyectos de este tipo: 1) Proyecto para la Gestión Integrada de Ecosistemas de la Cuenca Binacional del Río Sixaola. Este proyecto se trata de una donación, es de carácter binacional y es conocido por los actores locales como BID GEF; y 2) Programa para el Desarrollo Sostenible de la Cuenca del Sixaola, el cual es un préstamo que sólo se aplica en Costa Rica y es conocido por los actores locales como BID MAG.

La similitud entre ambos proyectos ha generado en los actores locales mucha confusión; la diferencia más importante es que el BID GEF es binacional y sus objetivos están más dirigidos a la conservación, mientras que el BID MAG, a pesar de que incorpora el tema ambiental, tiene un componente agrícola muy significativos.

Es importante destacar que estos proyectos son ejecutados con una participación activa de los ministerios de ambiente y agricultura. Sin embargo, el proyecto BID GEF cuenta con una Unidad Técnica Ejecutora con personal directamente financiado por el BID. 
Estos dos proyectos del BID han acudido para la ejecución de ciertas acciones a ONG locales y han generado alianzas con centros universitarios y de investigación como el CATIE para que estos realicen actividades de formación con organizaciones indígenas y asociaciones productoras de cacao.

\section{Proyectos de cooperación promovidos por alianzas público-} privadas. La Alianza Público Privada, proyecto que se basa en la responsabilidad social empresarial, articula capital público proveniente de la cooperación alemana a través de su agencia GIZ y capital privado proveniente del supermercado alemán REWE y de empresas bananeras. Este proyecto es ejecutado por la organización internacional RUTA a través de un equipo técnico conformado por personal de planta y una serie de consultores externos. Esta Alianza busca generar nuevas alianzas con organizaciones locales y con otras ONG que ejecutan proyectos en la zona para sumar esfuerzos y recursos. Este tipo de alianzas son cada vez más comunes; sin embargo, son muy cuestionadas debido a la incursión de capital privado en asuntos públicos, como en la conservación y gestión de un territorio.

A pesar de las diferencias ya expuestas entre estas tres modalidades de ejecución, al analizar el contenido de los proyectos se puede constatar que poseen elementos en común. Una primera observación es que la mayoría de estos proyectos propone acciones similares que se presentan casi como una "receta" que debe de aplicarse de la misma forma en territorios diferentes. Se pudieron identificar cuatro tipos de actividades propuestas por estos proyectos:

a. Investigación: es generalmente un paso inicial en los proyectos ya que muchos proponen la realización de diagnósticos o "líneas base" sobre el estado de los ecosistemas y sobre las necesidades de asistencia que tienen las poblaciones o públicos meta. Estas investigaciones son generalmente llevadas a cabo por consultores externos y buscan complementar las metas ya definidas en los proyectos. Generalmente esta etapa sirve sobre todo para identificar actores clave que sean influyentes y que puedan convertirse en potenciales aliados.

b. Formación: todos los proyectos identificados proponen acciones de capacitación para los actores locales generalmente alrededor de tres temas: actividades productivas más sostenibles, conservación del medio ambiente e incidencia política. En el tema de conservación se insiste en capacitar sobre temas ligados al manejo de desechos, gestión integrada de cuencas y adaptación al cambio climático. Esteúltimo es un tema recurrente en todos los proyectos.

c. Financiamiento de actividades productivas: los proyectos del BID y de la UICN proponen lo que ellos denominan fondos semilla o fondos de inversión. Estos fondos buscan financiar actividades productivas "limpias y justas" que a la vez permitan reducir la pobreza y la vulnerabilidad de las poblaciones ante el cambio climático.

d. Promoción de la "buena gobernanza". Muchos de estos proyectos plantean la creación de comités de cuencas o comisiones transfronterizas como espacios de participación activa donde los actores de base participen junto con las autoridades en la creación de políticas públicas.

¿Cómo funciona esta red de actores organizacionales transfronterizos para la conservación del ambiente?

Con el fin de comprender cómo opera esta red de actores transfronterizos, durante las entrevistas realizadas se solicitó a los actores entrevistados identificar quiénes eran, para ellos, los actores organizacionales más influyentes (ver gráfico l) y confiables (ver gráfico 2) en materia ambiental. Los gráficos 1 y 2 recuperan esta información y representan la complejidad de esta red. El tamaño de los círculos representa la cantidad de veces que los actores fueron mencionados por otros, mientras que las líneas grises representan las relaciones unidireccionales y las negras las relaciones que son reciprocas. 
El gráfico 1 ilustra a los actores organizacionales percibidos como los más influyentes. En él se puede observar cómo las instituciones estatales no son consideradas como los actores más influyentes, sino las OIG como el Proyecto BID GEF Sixaola. Se atribuye también un rol importante a la ONG local Corredor Biológico Talamanca Caribe, la cual ejecuta acciones tanto para el Proyecto BID GEF como para la UICN. Las asociaciones de desarrollo y las asociaciones indígenas son también consideradas influyentes, sobre todo las que fungen como autoridades indígenas, como la Asociación de Desarrollo Integral del Territorio Indígena Cabécar (ADITICA) y la Asociación de Desarrollo Integral del Territorio Indígena Bribri de Talamanca (ADITIBRI). Los gobiernos locales están poco representados, con excepción de la municipalidad de Talamanca. Es interesante observar la percepción que los actores tienen de la UICN, la cual, a pesar de tener dos proyectos en la zona, no es considerada como una de las más influyentes. Esto podría explicarse por el rol que desempeña el Corredor Biológico en los proyectos de esta ONG internacional, ya que las organizaciones locales ejecutan muchas de las acciones de sus proyectos. Es más, la oficina de la UICN en la zona está localizada en las oficinas del Corredor Biológico, situación que podría restarle visibilidad.

El gráfico 2, por su lado, presenta los actores considerados como los más confiables en relación con la conservación del ambiente. No es de extrañar que la organización considerada como la más confiable sea el Corredor Biológico. Muchas de las personas entrevistadas, sobre todo los representantes de las asociaciones de desarrollo, las autoridades indígenas y las cooperativas, destacaron la cercanía que tienen con esta organización. También resaltaron su experiencia y su conocimiento de la zona, así como el hecho de que sus equipos técnicos estén integrados por técnicos de la zona fronteriza. Además subrayaron el rol que ha cumplido esta ONG en anteriores conflictos socioambientales - lucha contra la exploración petrolera y contra la instalación de marinas-, momentos en los que generó denuncias y convocó a acciones colectivas. Las autoridades indígenas de ADITICA y ADITIBRI también fueron percibidas como actores confiables así como las escuelas, las cuales tienen un rol social muy importante, sobre todo en las campañas de recolección de desechos y de reforestación.

\section{Impacto y efectividad de los proyectos de cooperación en la cuenca transfronteriza del Sixaola}

Uno de los principales resultados de este proceso de investigación ha sido el constatar la falta de coordinación entre actores, dado que muchos de estos proyectos se ejecutan de forma simultánea o uno después del otro sin tomar en cuenta los aprendizajes generados por los proyectos que los precedieron. Además existe una comunicación muy limitada entre proyectos ya que muchas de las actividades tienden a repetirse. Se pudo además constatar una creciente falta de confianza en la cooperación internacional, puesto que muchas de las organizaciones locales entrevistadas, específicamente las autoridades indígenas - ADITICA y ADITIBRI- que participan actualmente en estos proyectos, afirmaron no haber participado en la elaboración de los mismos y por lo tanto consideran que su contenido no representa muchas de sus necesidades ni intereses.

Es evidente que las regiones fronterizas que nos ocupan se benefician de la inversión realizada por estos actores exógenos, pero a la vez su presencia ha generado una importante dependencia tanto de los recursos como de la asistencia técnica. Esta dependencia es aún más peligrosa si se toma en cuenta que los proyectos tienen una duración limitada que va de dos a cuatro años. Se pudo además observar que, al finalizar los proyectos, mencionados los actores locales no tienen capacidad financiera para mantener las actividades, situación preocupante si se toma en cuenta que, estos proyectos, plantean muchas veces acciones que requieren de largos procesos para concretarse, como planes de ordenamiento territorial o planes de gestión para las áreas protegidas. 
Se podría así afirmar que los actores exógenos, es decir, las ONG internacionales y los OIG, tienen diferentes temporalidades con respecto a las ONG locales y a las asociaciones indígenas y de desarrollo. La temporalidad hace referencia a las diferentes representaciones y percepciones que se tienen del tiempo: las temporalidades son múltiples y varían según las culturas (Picouet y Renard, 2007: 115). Los actores exógenos, desde una lógica más práctica de objetivos y resultados, perciben las actividades en tiempos cortos definidos generalmente por los marcos lógicos y los presupuestos de los proyectos. Por su parte, los actores locales se ven confrontados a la lógica global de la cooperación, la cual choca con su percepción del tiempo, en la cual los procesos se perciben como más largos, y los cambios como progresivos pero más perdurables. Estas dos temporalidades se ven confrontadas al momento de desarrollar los proyectos generando una importante tensión. Los actores exógenos ven a los actores locales como poco efectivos y como problemáticos, mientras que los actores locales, sobre todo las autoridades indígenas, al ver sus expectativas no cumplidas, cuestionan la efectividad de los proyectos.

\section{La cooperación internacional, ¿una comunidad epistémica?}

A través de sus foros y cumbres internacionales, la cooperación internacional ha generado todo un discurso que puede encontrarse fielmente representado en estos proyectos. Casi todos hacen mención a términos comunes como la gestión integrada de recursos hídricos, la gobernanza o la adaptación al cambio climático, ${ }^{12}$ entre otros. Sus acciones o metodologías se presentan en dichos proyectos como estrategias validadas por una comunidad epistémica para luchar contra los "avatares del cambio climático" o para mejorar la gestión del riesgo en los poblados fronterizos. Esta comunidad estaría conformada por expertos internacionales que se reúnen en grupos de reflexión a escala global, como es el caso, por ejemplo, del Grupo Intergubernamental de Expertos sobre el Cambio Climático (IPCC),${ }^{13}$ creado en 1988, el cual analiza "la información científica, técnica y socioeconómica relevante para entender el cambio climático provocado por las actividades humanas."

El paradigma Gestión Integrada de Recursos Hídricos (GIRH) esun concepto que nace desde el mundo de los organismos de cooperación internacionales. El concepto de cuenca no es reciente, pero la idea de gestionar el agua desde esta unidad sí lo es ${ }^{14}$ (Lasserre y Brun, 2012: 2). La GIRH es definida por el Global Water Partnership (GWP) ${ }^{15}$ como "un proceso que promueve el manejo y desarrollo coordinado del agua, la tierra y los recursos relacionados, con el fin de maximizar el bienestar social y económico resultante de manera equitativa sin comprometer la sustentabilidad de los ecosistemas vitales" (Asociación Mundial para el Agua, 2000: 26). La GIRH promueve así una serie de conceptos y principios clave que a lo largo de los años han tratado de difundir entre científicos, técnicos y gestores del agua. A partir de la década de los noventa, la noción de GIRH se incorpora paulatinamente a las legislaciones nacionales ligadas a la gestión del agua. Desde 1993, los Estados en vías de desarrollo que deseaban solicitar préstamos al Banco Mundial para proyectos hidráulicos tuvieron como condición adoptar una "buena" legislación en materia de agua que incorporara este paradigma (Trottier, 2012: 191).

El concepto de GIRH se convirtió en un concepto clave, casi irrefutable, a través del cual se incorporaron principios como los de participación, "buena gobernanza" o cuenca hidrográfica, entre otros. La GIRH introduce así el concepto de cuencas hidrográficas como la unidad ideal de manejo del recurso hídrico (Hernández, López y Jiménez, 2009: 16). En estos proyectos hay una aceptación casi generalizada de la necesidad de hacer una gestión del territorio por cuencas, de manera que en muchos de ellos se utiliza la delimitación de la cuenca del Sixaola como unidad de ejecución. Pero, aun cuando la gestión por cuencas propone gestionar el espacio de forma integrada, traspasando la fragmentación política que implican las fronteras, esta metodología ha demostrado en la práctica ser de difícil aplicación, ya que hoy en día en esta región de frontera, aparte de esfuerzos muy puntuales, no se puede decir que existan verdaderas experiencias 
de gestión integrada de cuencas. Además, se pudo observar durante las entrevistas que la apropiación de este concepto por los actores locales sigue siendo muy limitada.

Las ONG internacionales, así como los OIG, disponen de una creciente influencia política tanto en lo local, como en lo nacional y regional. Al participar activamente y convocar a foros y cumbres internacionales, influyen directamente en las directrices globales en materia ambiental - Iniciativa Agua y Naturaleza o Lista de Especies en peligro, entre otras-. Han logrado llevar estas directrices a las esferas nacionales y locales, fungiendo así como difusoras y traductoras de tales acuerdos globales. Esto se puede observar en la región centroamericana, dado que muchas de estas organizaciones internacionales han ejercido como asesoras de tomadores de decisión tanto a escala regional (SICA), como a escala nacional y local. Éste ha sido el caso de TNC y UICN en materia de cambio climático, y de GIRH.

En los proyectos de la UICN, de TNC o de la Unidad Técnica del proyecto BID GEF se motiva la participación directa y la horizontalidad en los procesos de toma de decisiones. El proyecto BID GEF, con el apoyo técnico de la UICN, ha motivado la creación del Comité para la Gestión Binacional de la Cuenca del Sixaola. Este comité, que busca fungir como un espacio de "gobernanza", cuenta con la participación de la sociedad civil - representantes indígenas-, de representantes de los ministerios de salud, agricultura y ambiente de Costa Rica y Panamá, así como de representantes de las comisiones de emergencias.

El concepto de gobernanza lo retoman de la década de los años ochenta los expertos de las grandes agencias internacionales de ayuda para el desarrollo, y especialmente el Banco Mundial. La "buena gobernanza", como ejemplifica el concepto de GIRH, aparece como la "nueva receta" que los expertos internacionales presentan para mejorar los procesos de gestión, motivando la participación de múltiples sectores e incorporando los criterios de eficacia en la toma de decisión (Hermet, Kazancigil y Prud'homme, 2005: 6). La gobernanza plantea un nuevo modelo de ejercicio de poder en sociedad e implica participación pública, así como una visión descentralizada del poder. Este poder está en red, ya que el poder, los recursos y la información están distribuidos entre los diferentes actores (Létourneau, 2011: 3).

La incidencia política y la gobernanza están presentes en estos proyectos como acciones prioritarias. Todos buscan desarrollar en las organizaciones locales capacidades para el lobby político y promueven la creación de plataformas de gobernanza, las cuales se conciben como espacios de participación, de debate y de toma de decisión.

Se pudo constatar que las decisiones por tomar tienen muchas veces una relación directa con las actividades propuestas por los mismos proyectos. Los actores exógenos justifican la existencia de estas plataformas al afirmar que son un medio más eficaz para ejecutar y dotar de legitimidad a las acciones de sus proyectos, pasando al margen de la burocracia del Estado. En la cuenca del Sixaola, su modo de funcionamiento depende profundamente de estos proyectos ya que son estos actores exógenos los que convocan y financian sus reuniones. Actualmente ninguna de las comisiones o de los comités creados ha logrado ser institucionalizado, pero aspiran a ello. Por el momento, los acuerdos que se desprenden de estos comités son provisorios y revocables. En efecto, al no estar institucionalizados, las decisiones que se toman en estos espacios son el resultado de un debate informal y no son representativas, ya que sólo ciertos sectores de las comunidades participan. Los acuerdos resultantes de estas plataformas, a diferencia de las leyes o de los acuerdos de cooperación - que son votados bajo el principio de mayoría-, son negociados por minorías generalmente integradas por organizaciones locales aliadas de las organizaciones internacionales (Hermet, Kazancigil y Prud'homme, 2005: 10).

Desde la percepción de los actores entrevistados, el Estado no ha dejado de estar presente pero ya no aparece como el actor único o central. El rol del Estado en este nuevo escenario es puesto en duda ya que asume un rol de animador o de catalizador, cediendo 
su rol protagónico, tal como podemos observar en el gráfico 1. Autores como Stoker afirman que, en la práctica, entre lo privado, lo estatal y la sociedad civil ya no existe una verdadera jerarquía (Létourneau, 2011: 3). De esta forma, se observa una inserción de actores privados en las redes de poder y se empieza a observar cómo alianzas público-privadas buscan gestionar los servicios públicos.

La creciente influencia de actores exógenos ha suscitado diversos cuestionamientos; por un lado, algunos afirman que su rol ha debilitado la autoridad de los gobiernos locales y nacionales poniendo en duda su soberanía. Otros consideran que estos actores responden a una necesidad real, a un vacío que los Estados son incapaces de suplir. Con respecto a las plataformas de gobernanza creadas, al estar íntimamente ligadas a los proyectos, muchos piensan que en realidad tienen como único fin dotar a los proyectos de legitimidad.

\section{Conclusiones}

Existe efectivamente una relación ineludible entre las fronteras centroamericanas y el ambiente. Tanto a nivel mundial como en la región centroamericana, las fronteras fueron instrumentalizadas y naturalizadas durante la década de los noventa como una estrategia para motivar la cooperación entre países a través de la conservación del medioambiente. No es de extrañar, por tanto, que alrededor de ellas existan numerosas iniciativas de cooperación internacional que buscan conservar la biodiversidad y los recursos hídricos que en ellas se encuentran — cuencas hidrográficas-. A través de estos proyectos, los actores exógenos han logrado introducir en la gestión local sus preocupaciones e intereses, así como todo un vocabulario — adaptación al cambio climático o gestión integrada de cuencas, entre otros- y por lo tanto influir en la acción pública local, nacional y regional.

Ciertamente, los actores exógenos ejercen una importante influencia -recursos, reconocimiento y legitimidad - en la gestión ambiental de estas regiones fronterizas, si bien han venido a llenar algunos vacíos históricos e institucionales dejados por el aparato gubernamental. También han sacado provecho de la particularidad de estas regiones para poner en práctica sus proyectos debido a que consideran que cuentan con mayor autonomía con respecto a otros territorios en donde los Estados tienen una mayor presencia.

Si bien estas regiones transfronterizas están en una posición periférica con respecto a sus propios países, la presencia de actores exógenos las conecta con un sistema oligopólico a escala global. Las ONG internacionales y los OIG están ocupando la posición de agentes políticos mundiales cuya estructura descentralizada -oficinas regionales y aliados locales - articula, de forma directa y sin pasar por intermediarios estatales, lo global con lo local (Dumoulin y Rodary, 2005: 84). El discurso de la universalidad de la naturaleza justifica así el no pasar por la escala nacional y los legitima con actores globales.

Su capacidad de ejecutar acciones a través de ONG locales, las cuales cuentan con legitimidad, dota de factibilidad a sus proyectos. Estas ONG locales se han convertido en intermediarias entre las oficinas regionales de las ONG internacionales y de los OIG, y las organizaciones de base - asociaciones de desarrollo, cooperativas y autoridades indígenas - fungen además de traductoras de los términos técnicos y científicos creados desde los foros y grupos de trabajo por expertos internacionales.

Si bien el rol que han ejercido ha sido determinante, su discurso y el modo de ejecución de sus proyectos ha sido cuestionado. Una de las principales críticas es que muchos de estos proyectos han sido concebidos por equipos técnicos sin una verdadera participación de actores locales. Otro cuestionamiento clave ha sido su discurso de "buena gobernanza", a través del cual se ha justificado el establecimiento de comités o comisiones que, para el caso de la cuenca del río Sixaola, buscan gestionar la cuenca de manera participativa. Muchos funcionarios públicos consultados ven en esto una amenaza ya que temen la creación de un sistema paralelo de gestión que resta control y protagonismo al Estado. También se ha cuestionado la incursión en estos espacios de gobernanza de actores privados como empresas-, los cuales participan codo a codo con actores públicos introduciendo sus propias 
agendas, las cuales no siempre corresponden a la lógica propia de la acción pública: el bien común.

\section{Notas}

${ }^{1}$ Esta falta de vigilancia y porosidad es particularmente característica de las fronteras de Centroamérica. No es efectivamente el caso de la frontera Estados UnidosMéxico, la cual se caracteriza por su seguridad y vigilancia.

${ }^{2}$ Los puntos ciegos son segmentos fronterizos en los cuales hay una falta de control y vigilancia por parte de las autoridades locales y nacionales. Generalmente, en estos segmentos el tráfico de personas se da de manera informal sin pasar por controles migratorios o aduaneros. Los puntos ciegos son frecuentemente aprovechados para el contrabando y el narcotráfico.

3 Las fronteras centroamericanas se consideran estratégicas internacionalmente en la lucha contra el narcotráfico emprendida por diferentes países y apoyada particularmente por Estados Unidos, país que las ve como sus propias fronteras.

${ }^{4}$ Un importante ejemplo es el acuerdo firmado en 1995 por los vicepresidentes centroamericanos para el desarrollo sostenible fronterizo, elaborado gracias al apoyo brindado por la OEA, la Secretaria de Integración Económica Centroamericana y la Fundación para la Paz y la Democracia. Este acuerdo ve el desarrollo de las zonas fronterizas como un instrumento para reforzar los lazos entre los países y, por consiguiente, la integración (Medina, 2009: 42).

5 Desde el siglo XIX, los actores exógenos de origen transnacional como las empresas bananeras United Fruit Company y Chiquita Land Company han desempeñado un rol determinante tanto en el trazado del límite fronterizo como en las dinámicas transfronterizas que se han desarrollado.

${ }^{6}$ La Unión Internacional para la Conservación de la Naturaleza es la primera organización internacional dedicada a la protección del ambiente inicialmente a través la creación de parques naturales. Se creó en 1947 con participación de la sociedad civil y de 23 Estados.
${ }^{7}$ El desarrollo sostenible nace en 1987 del cruce entre las preocupaciones ambientalistas y la ideología desarrollista con motivo de la preparación de la Conferencia Mundial de las Naciones Unidas sobre Medio Ambiente y Desarrollo, realizada en Río de Janeiro, Brasil, en 1992. Es utilizado por primera vez en el Informe Brundtland.

${ }^{8}$ Ver http://www.oas.org/dsd/WaterResources/projects/ ISARM/Publications/ISARMAmericasLibrol(spa).pdf. ${ }^{9}$ La Unidad Regional de Asistencia Técnica (RUTA) es una iniciativa conjunta interagencial y gubernamental de los siete países centroamericanos (Belice, Costa Rica, El Salvador, Guatemala, Honduras, Nicaragua y Panamá) y de siete agencias internacionales de desarrollo (MAEC, FIDA, ADA, BID, FAO, IFPRI y IICA) para fomentar el desarrollo sostenible y la reducción de la pobreza en las áreas rurales de Centroamérica. Ver: http://www.ruta.org/historia_ de_ruta.php.

${ }^{10}$ La milla marítima o la zona marítimo-terrestre es la franja de 200 metros de ancho situada a lo largo de los litorales (Pacífico y Atlántico) que constituye parte del patrimonio nacional. Pertenece al Estado costarricense y es inalienable e imprescriptible.

${ }^{11}$ Área protegida compartida por Costa Rica y Panamá.

${ }^{12}$ Definida por el IPCC como el ajuste de los sistemas humanos o naturales al cambio climático actual y al esperado. La adaptación puede ser reactiva, o sea después de la manifestación, o planificada, es decir, anticipatoria.

${ }^{13}$ Ver: http://www.ipcc.ch/home_languages_main_spanish. shtml\#.UWUT-L-eeQs.

14 Es el geógrafo Philippe Buache (1700-1773) el primero en formalizar este concepto, el cual define cuenca hidrográfica como una porción del territorio delimitado por líneas de crestas cuyas aguas desembocan ya sea en el mar o en otro curso de agua (Lasserre y Brun, 2012: 2).

${ }^{15}$ La GWP es una institución fundada en 1996 por el Banco Mundial, el Programa de las Naciones Unidas para el Desarrollo, la Swedish International Development Agency y el World Water Council. 
Fue creada para ser un thinktank, es decir, un grupo de reflexión internacional sobre las problemáticas de agua. En la actualidad funge como una red que agrupa múltiples actores, como organizaciones no gubernamentales, agencias de las Naciones Unidas, instituciones financieras, empresas, universidades y organizaciones de cuenca (Trottier, 2012: 180).

\section{Bibliografía}

Amilhat-Szary, Anne Laure y Marie Christine Fourny (2006), Après les Frontières, avec la Frontière: Nouvelles Dynamiques Transfrontalières en Europe, Francia: Éd. de l'Aube.

Bovin, Philippe (coord.) (1997), Las fronteras del Istmo: fronteras y sociedades entre el sur de México y América Central, México: Centro de Investigaciones y Estudios Superiores en Antropología Social.

Asociación Mundial para el Agua y Comité de Consejo Técnico (2000), Manejo integrado de recursos hídricos, Estocolmo: Global Water Partnership.

Asociación Mundial para el Agua y Comité de Consejo Técnico (2011), Situación de los recursos hídricos en Centroamérica: hacia una gestión integrada, Tegucigalpa: la Asociación.

Debarbieux, Bernard (2006), "La nature inconstante des relations entre nature et frontière", en Héléne Velasco-Graciet y Christian Bouquet, Tropisme des frontières: Approche pluridisciplinaire, París: L'Harmattan, Géographic et Cultures, pp. 77-81.

Debray, Régis (2010), Eloge des frontières, Francia: Gallimard.

Dumoulin, David y Estienne Rodary (2005), "Les ONG, au centre du secteur mondial de la conservation de la biodiversité", en Représenter la nature. ONG et biodiversité, París: Presse de l'IRD, pp. 59-99.

Foucher, Michael (1991), Frontset frontières: un tour du monde géopolitique, París: Fayard.

Foucher, Michael (1997), "Tipologías de las fronteras contemporáneas”, en Philippe Bovin (coord.), Las fronterasdel Istmo:fronterasy sociedadesentreel sur de México y América Central, México: Centro de Investigaciones y Estudios Superiores en Antropología Social.
Fourny, Marie Christine (2005), "De la frontière naturelle à la nature comme lien transfrontalier. $\mathrm{Du}$ rôle et de la place de l'environnement et du milieu dans les coopérations transfrontalières", en Héléne Velasco-Graciet y Christian Bouquet, Tropisme des frontières: Approche pluridisciplinaire, París: L'Harmattan, Géographic et Cultures, p. 209.

Franklin, H. (2007), Costa Rica-Panamá, Gestión integrada de ecosistemas en la cuenca del río Sixaola. Documento de Proyecto. Banco Interamericano de Desarrollo (inédito).

Gay, Jean Christophe (2004), Les discontinuités spatiales, París: Economica.

Girot, Pascal y Carlos Granados (1997), “La Cooperación Transfronteriza y Los Nuevos Paradigmas De La Integración Centroamericana", en Philippe Bovin (coord.), Las fronteras del Istmo: fronteras y sociedades entre el sur de México y América Central, México: Centro de Investigaciones y Estudios Superiores en Antropología Social.

Hernández Ulate, Aurora, Alexander López Ramírez y Alicia Jimenez Elizondo (2009), Gobernabilidad e instituciones en las cuencas transfronterizas de América Central y México, Costa Rica: FLACSO.

Hermet, Guy, Ali Kazancigil y Jean-Francois Prud'homme (2005), La gouvernance: un concept et ses applications, París: CERI/Karthala.

Lasserre, Frédéric y Emmanuel Gonon (2008), Manuel de géopolitique: enjeux de pouvoir sur des territoires, París: Armand Colin.

Lasserre, Frédéric y Alexandre Brun (2012), Gestion de l'eau: approche territoriale et institutionnelle, Québec: Presses Universitaires de Québec.

LeBerre, Maryvonne (1992), "Territoires", en Bailly, Antoine, Robert Ferras y Denise Pumain (coords.) Encyclopédie de la géographie, París: Economica, pp. 617638.

Létourneau, Alain (2011), "Les théories de la gouvernance. Pluralité de discours et enjeux éthiques", en VertigO. La Revue Électronique en Sciences de L'environnement, núm. 10.

Machado de Oliveira, Tito Carlos (2009), "Frontières en Amérique Latine: Reflexions Méthodologiques", en Espaces et Sociètés, núm. 3. 
Maganda, Carmen (2008), “iAgua dividida, agua compartida? Acuiferos transfronterizos en Sudamérica, una aproximación", en Estudios Políticos, núm. 32, pp. 171-194.

Matul, Daniel(2007), "Vecindad, cooperación y confianza mutua: una revisión", en Revista Centroamericana de Ciencias Sociales, núm. IV (1), pp. 77-l14.

Medina, Lucile (2009), "Les frontières de l'isthme Centraméricain, des Marges Symboliques à des Espaces en Construction", en Espaces et Sociètés, núm. 138, pp. 35-50.

Morales, Aberlardo (2010), “Desentrañando fronteras y sus movimientos transacionales entre pequeños Estados. Una aproximación a la frontera Nicaragua-Costa Rica", en María Eugenia Anguiano y Ana María López, Migraciones y fronteras: nuevos contornos para la movilidad internacional, Barcelona: CIDOB, Fundación Antrazyt.
Picouet, Patrick y Jean Pierre Renard (2007), Les frontières mondiales: origines et dynamiques, Nantes, Francia: Editions du Temps.

Reitel, Bernard y Patricia Zander (2004), "Espace transfrontalier", en Hypergeo, núm. 3.

Rodriguez, Tania (2009), Vecinos entre fronteras: experiencia de las comisiones transfronterizas locales del proyecto Alianzas de la UICN como plataformas de cooperación y gobernanza ambiental sescentralizada. 2004 - 2008, UICN, Oficina Regional de Mesoamérica.

Trottier, Julie (2012), "L'avènement de la gestion intégrée des ressources en eau", en Lasserre, Frédéric y Alexandre Brun, Gestion se l'eau: Approche territoriale et institutionnelle, Québec: Presses Universitaires de Québec.

Velasco-Graciet, Héléne y Christian Bouquet (2006), Tropisme des frontières: Approche pluridisciplinaire, París: L'Harmattan, Géographic et cultures.

Tabla 1

Proyectos y programas para la conservación de los ecosistemas localizados alrededor de la cuenca del Sixaola

\begin{tabular}{|c|c|c|c|c|c|}
\hline Cuenca & Países & Superficie en $\mathbf{k m}^{2}$ & Población & $\begin{array}{c}\text { \% de la cuenca en } \\
\text { cada país }\end{array}$ & $\begin{array}{c}\% \text { de la población residente } \\
\text { en cada país }\end{array}$ \\
\hline \multirow{2}{*}{ Sixaola } & Costa Rica & \multirow{2}{*}{2839,6} & \multirow{2}{*}{119539} & $81 \%$ & $58 \%$ \\
\hline & Panamá & & & $19 \%$ & $42 \%$ \\
\hline
\end{tabular}

Fuente: Asociación Mundial del Agua (2011: 21) y Hernández, López y Jiménez (2009: 58). 


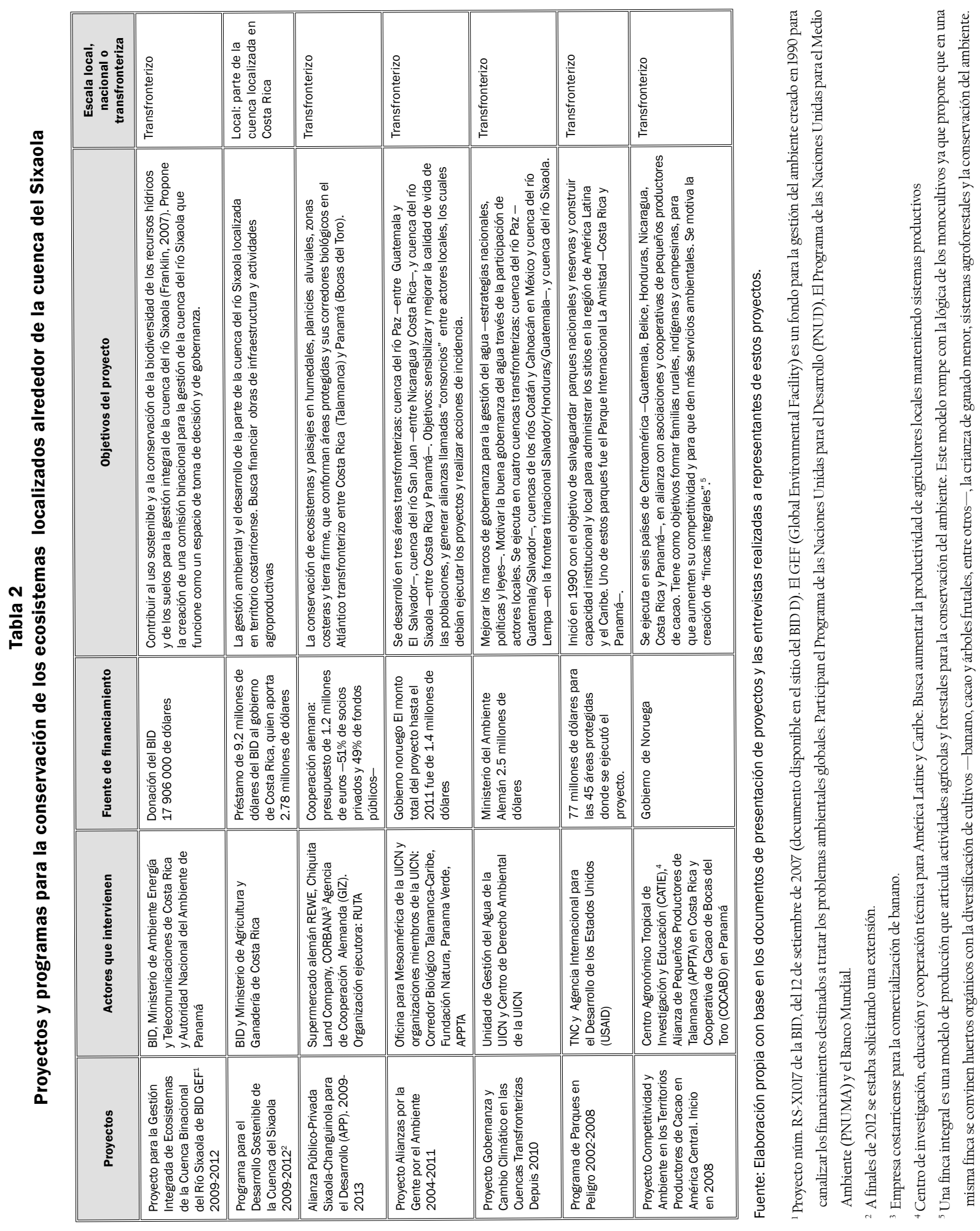


Mapa 1

Localización de la cuenca del río Sixaola con respecto a Centroamérica

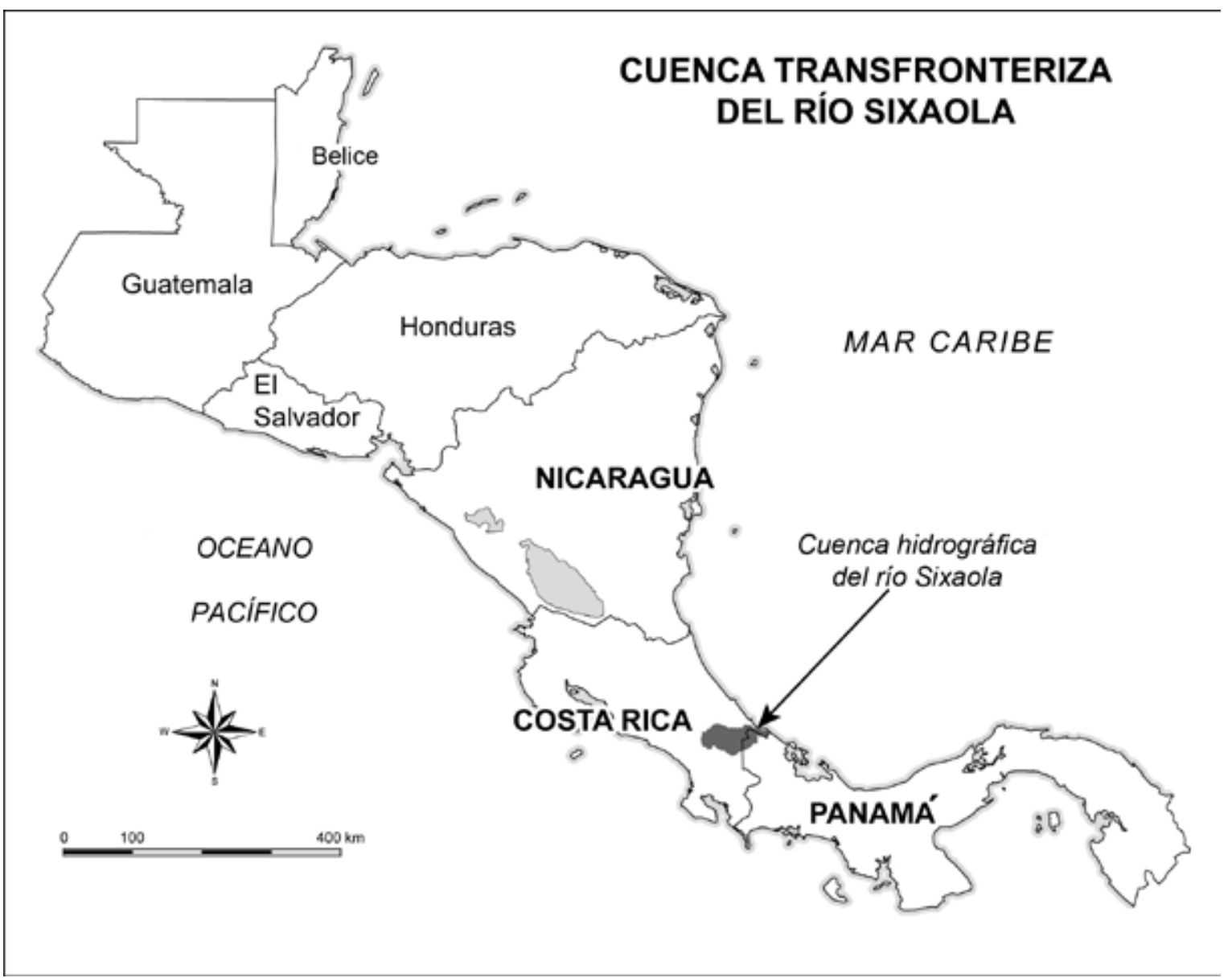

Autores: T. Rodríguez (SEDET) y A. Christol (LGP), 2012.

Fuente: Mapa de cuencas transfronterizas de Centroamérica, Comisión Centroamericana de Ambiente y Desarrollo (CCAD), 2004. 
Gráfico 1

Actores más influyentes

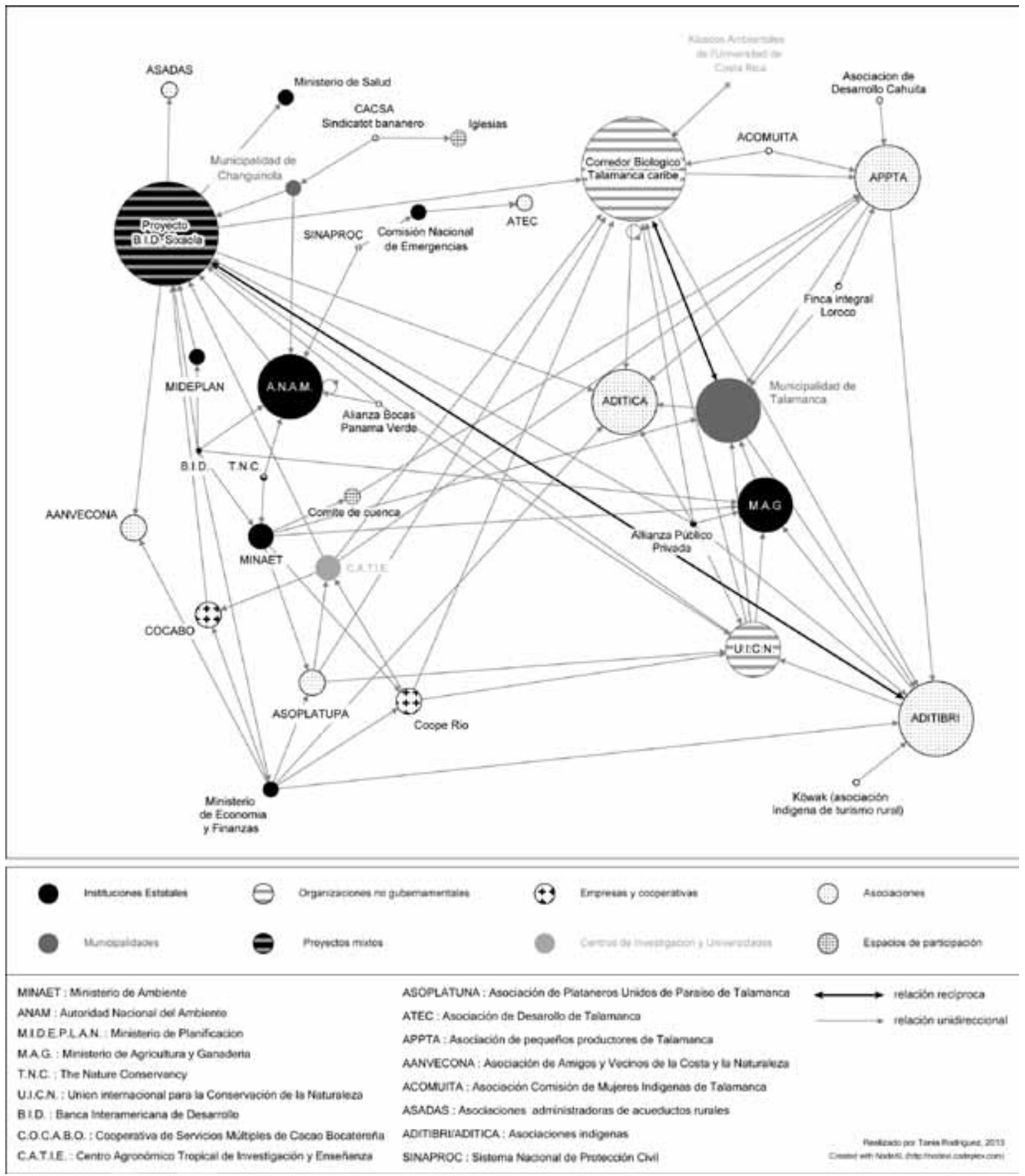


Grafico 2

Actores que generan más confianza

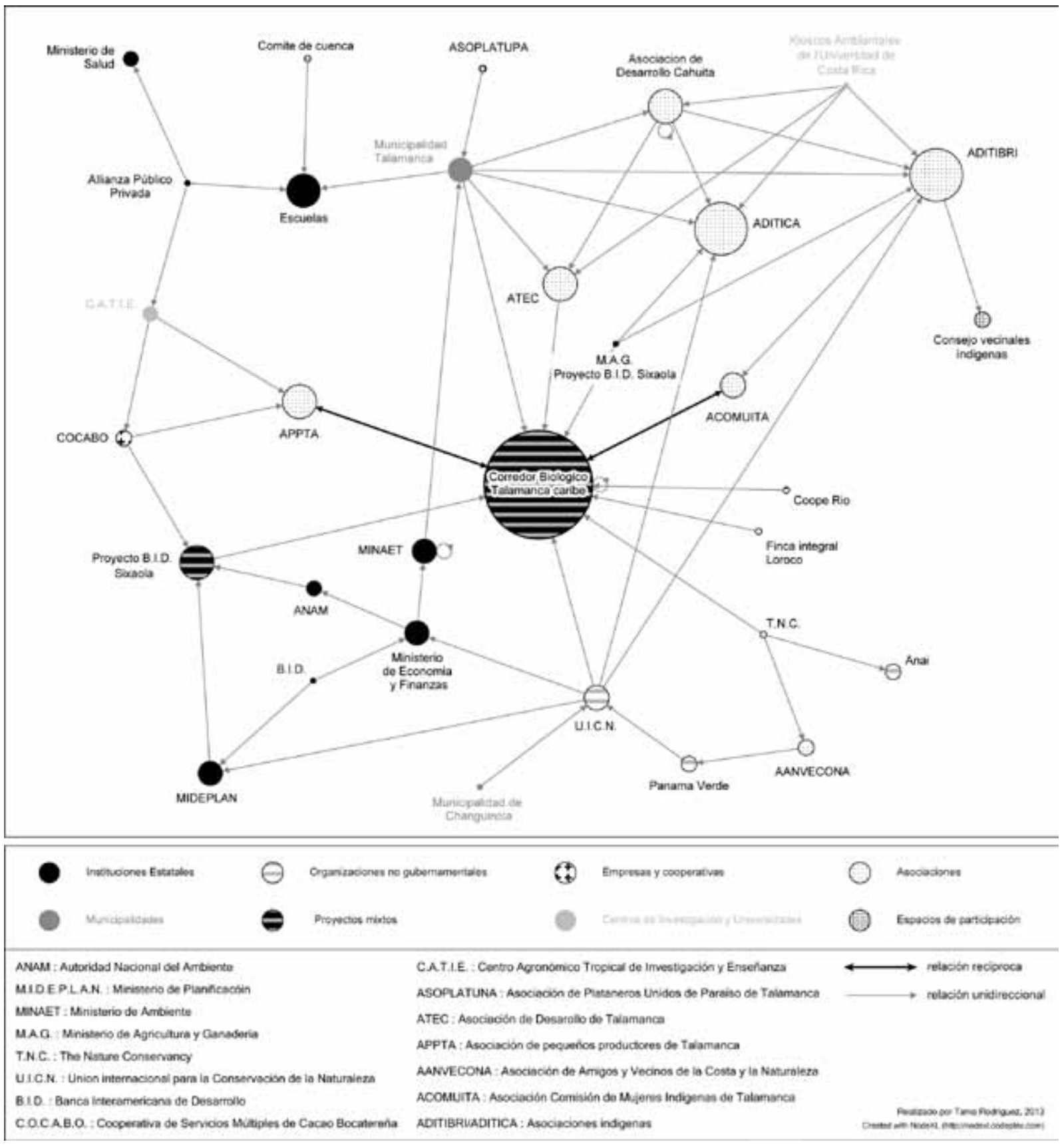

